\title{
Dam Yield Assessment In Selangor 2016
}

Heng Hock Hwee, Associate Director, SMHB Sdn Bhd

Hii Ching Poon, Independent Consultant

Siaw Fei Lu, Senior Lecturer, Faculty of Engineering and the Built

Environment, SEGi University

Pan Wang Fook, Senior Lecturer, Faculty of Engineering and the Built Environment, SEGi University

\begin{abstract}
This paper presents a review of water yields for six reservoir schemes within Selangor and Kuala Lumpur. The study was carried out using up-to-date hydrometric database up to 2009. Three approaches were used for yield calculations; namely, (1) Drought Sequence, (2) Longterm records, and (3) Storage-yield-reliability model techniques/methodologies. It was found that the gross yields of various reservoir schemes were agreeable with one another, at least within the margin of difference which is about $5 \%$.
\end{abstract}

\subsection{Introduction}

This study presents a reliable yield review of the existing dams for the water supply system in the state of Selangor and Kuala Lumpur, Malaysia. A well designed reservoir scheme should be able to fulfill its intended fucntions, such as to provide raw water augmentation to respective water treatment facility and to ensure adequate flow to turn the turbine for electricity generation, in the case of hydropower scheme.

The study only limits to the assessment and verification of reliable yield estimation using available secondary hydrometric information and uniform techniques/methodologies. The need of this assessment is considered as an integral part of the regular exercise in ensuring continuous operation of the existing water supply reservoir schemes.

There are six major reservoir schemes in the state of Selangor, Malaysia. These dams were significant parts of the domestic water supply schemes to the capital city and its fast growing suburban 
development nearby. The dam schemes in total provide about 4900 Mld of treated water to various demand areas in Selangor and Kuala Lumpur. Total maximum reservoir capacity is about $490 \mathrm{MCM}$.

\subsection{Problem Statement}

The design standard for water supply system in Malaysia was generally based on the selection of the most severe low flow streamflow records, preferably of more than 30 years of length. However, this minimum length of database somehow could not be met due to a lack of gauging station network and database especially when the dams were designed in the earlier 1960's.

To overcome this weakness of short records and data unavailability, a drought sequence approach (DSA) was adopted at that time, and in essence the low flow series was derived from the limited length of database to represent the low flow regime of a given probability of occurrence or return period.

Over the years, with additional flow records made available, it would be appropriate to carry out a review on the reservoir yield and perhaps timely remediation action could be taken if the schemes are found to be deficient. In addition, an extension of the hydrometric records in essence includes the most recent El Nino induced low flow events (ENSO episode). The extensive drought occurrence from 1997-1998 was one of the worst in the $20^{\text {th }}$ century, and the information was of utmost importance to the water resources planning and development endeavors. A newly derived DSA based on extensive longer records would be of help to confirm adequacy and consistency of the yield results vis-à-vis the previous undertaking during the design stage of the reservoir/dam scheme.

\subsection{Description of the River Basins}

The Selangor river basin is the largest river basin in Selangor where it drains some $1800 \mathrm{~km}^{2}$ at the estuary. The river basin is undulating landform with mixed land use practices, mainly consisting of forest and minor agricultural based plantations. It remains primarily rural with only sporadic townships scattered along the main stem of the river.

Two dams, Tinggi and Selangor dams (40 and $197 \mathrm{~km}^{2}$ in catchment areas) are located in the upper basin to provide augmentation flows to 
the downstream intakes near the estuary. These two dams forms major water supply scheme to Selangor and Kuala Lumpur as they constitutes some $60 \%$ of the total demand. A 150-Mld capacity pump refill scheme was also implemented to speed up refilling of Tinggi reservoir.

The Langat river basin forms the southernmost boundary of the State of Selangor and a small portion of the drainage area partially intrudes into the neighboring State of Negri Sembilan. The upper catchment in the vicinity of the dam site comprises generally rugged and undulating mountain terrain with multiple rural land use classification. However, the vast majority of the land use remains as undisturbed primary forest especially in non-accessible and remote regions of the upper river basin.

Two (2) major existing dams, Langat and Semenyih dams (41 and 57 $\mathrm{km}^{2}$ in dam catchment area) are located in the headwater tributaries of Langat river basin. This combined output of about 1000 Mld was the largest in the Langat river basin until it was surpassed by the Selangor river water supply scheme of ultimate 3000 Mld in the late 1990's.

Klang Gates and Batu dams are located in the upper headwater catchment of Klang river basin; drain some 77 and $50 \mathrm{~km}^{2}$ of catchment areas respectively. The reservoir storage capacities (combined live storage of about $47 \mathrm{MCM}$ ) and reliable yields are only a small fraction of Selangor, Langat, and Semenyih dams. Total plant capacity of these dam schemes is about $250 \mathrm{Mld}$.

Both dams are also being operated as flood control reservoir where substantial reservoir capacities above the full supply level are reserved for flood waters in time of monsoonal season. Therefore, their potentials for future upgrading and retrofitting are basically limited. A 45-Mld Wangsa Maju WTP also taps raw water sources directly from Klang Gates reservoir during normal flow regime. When the reservoir water level reaches a pre-designated low level, the diversion would therefore stopped, and is augmented by a pumping scheme from neighboring Gombak river basin.

Compared to others, Subang lake reservoir/dam is a much smaller water supply scheme commissioned in the earlier 1950's. It drains a smaller tributary of Buloh River, to the northwestern corner of Klang river basin. It is located $30 \mathrm{~km}$ west of Kuala Lumpur to supply 
mostly the western coastal region of Selangor. The dam that drained about $10.3 \mathrm{~km}^{2}$ of the catchment area provides a steady raw water source to North Hummock WTP of about 23 Mld in capacity. The yield was known to be slightly lower and the WTP is almost operated under overloading condition. There are also more than 20 smaller capacity run-of-river schemes within the state of Selangor and Kuala Lumpur. Some of these schemes are located outside of the reservoir river basin. Their raw water diversions are therefore not being considered in the reservoir yield calculation. Figure 1 shows the location of various dam in the state of Selangor, Malaysia

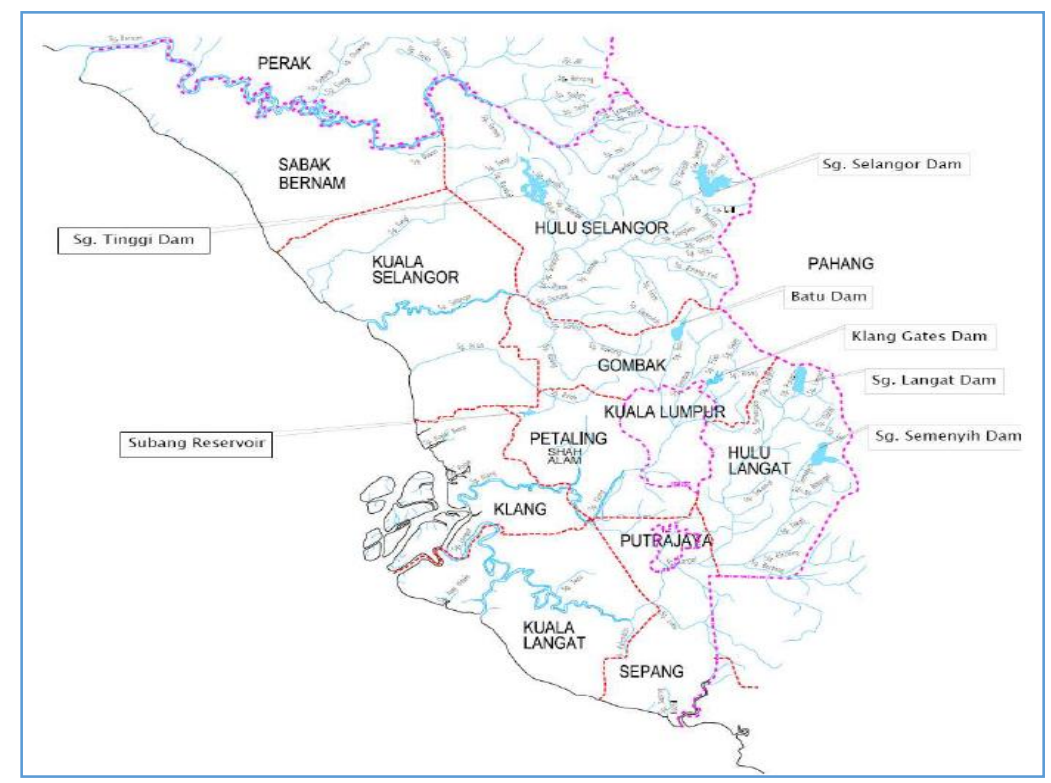

Figure 1: Dam Location in the State of Selangor and Kuala Lumpur

\subsection{Objectives and Purposes}

The objectives of this Study are to: estimate the reliable yields of major reservoir schemes in Selangor, i.e. Selangor-Tinggi, Langat, Semenyih, Klang Gates, Batu, and Subang Lake schemes using up-todate hydrometric information, uniform techniques and methodologies. In addition, further work was carried out to compare yield results 
using global water model Storage-yield-reliability (SYR) by Kuria and Vogel (2014).

\subsection{Literature Review}

The design standard of the water supply system in Malaysia is based on the selection of the most severe streamflow records, preferably of more than 30 years of length. However, this length of database is not available due to a lack of gauging station network not only in project areas but over the entire country. To overcome this weakness in data availability, a stack drought sequence approach is devised to derive the lowest flow time series of a given probability of occurrence. This technique is known as the Twort's Drought Sequence Approach (DSA).

The sequence is derived based on limited length of records, by inferring low flow of a specific return period, or probability in the occurrence of low flow. A low flow sequence can then be used as input to estimate the reliable yield of a reservoir system by a simple water balance calculation. The deficit/surplus at the end of the time step represents the drawdown or spillover of the dam crest. By convention, reliable yield should be reviewed using latest hydrometric information. In the context of this study, the reliable yield shall denote as "continuous water supply and availability for a given probability of occurrence and/or reliability." (Johnson et al., 2009).

The continuity on water supply that could be maintained throughout the design drought period i.e. 1:50-year drought or 2\% drought is normally adopted in Malaysia. On the other hand, in the case of runof-river yield, the reliability of the water resources availability is based on 1:50-year return period and for various average-day durations, such as 7-, 14-, and 30-day. Extra measure is also incorporated in the design criteria for both direct supply and regulating reservoir scheme. The primary purpose of this criterion is to ensure timely refilling of the reservoir after a continuous period of drawdown during a prolonged dry season. Normally for meteorological and hydrological characteristics of Malaysia, a 36month carryover period is specified in tandem with the 1:50-year 
return period criteria. However, depending on the prevailing circumstances, a slight extension of more than 36 months is sometimes permitted.Figure $\mathbf{2}$ shows the DSA for Langat dam scheme.

The carryover period (also commonly known as critical period) is defined in the context of this study as the period, daily or monthly, firstly from depleting the reservoir storage from full level to empty at the top of the dead storage elevation or level. Starting from this point, the reservoir enters the refilling phase up to the full supply level of the reservoir. This unique carryover period of 36 months duration is imposed to ensure that the reservoir will be refilled after an earlier depletion and continued drawdown period of 1:50-year severity. In contrast, if the carryover period is extended beyond 36 months, this essentially means a lesser stringent rule on the yield and capacity of the reservoir scheme. Correspondingly, a higher yield can be harnessed if the rule on carryover period is further relaxed.

For clarity, gross yield is defined as the total constant reservoir supply of water for the design drought periods, whereas, the net yield is a continuous supply of water that could be obtained after subtracting deductions such as prior compensation releases, irrigation allocations and other requirements. Other than the DSA technique, a long-term water balance calculation is also carried out in tandem. This longterm run takes advantage of long term inflow into the reservoir. The method of water balance calculation is similar to the DSA approach but with a much longer inflow records (McMahon and Mein, 1986; Nagy et al, 2002, McMahon and Adoyele, 2005). These two (2) techniques basically complement each other in terms of reservoir yield estimation albeit using different length of records and interpretation. The differences in yield by respective yield estimation techniques appear to be marginal and mostly were confined within the same order of magnitude. Nowadays with longer length of essential hydrometric records, it is the trend that both techniques are being commonly adopted in the water resources planning in Malaysia. This technique of utilizing long term observed hydrometric records was introduced in McMahon and Mein (1986), Nagy et al. (2002), 
McMahon and Adeloye (2005), WMO (2008) and practiced in the USA and Australia.

These two different modes of assessment or technique is mainly comparable at least on the same order of magnitude in terms of reliable yield concerned. Experiences in water supply dams in Malaysia occasionally reported slightly higher yield harnessed using long term water balance operation technique. One of the primary differences between DSA and long term approaches is none other than the definition of the yield and their quantitative meaning in interoperating the results. Both techniques however seek to draw the reservoir level down to the bottom of the live storage while leaving the dead storage capacity untouched (these are normally presented in the reservoir drawdown curves for various design and operational scenarios).

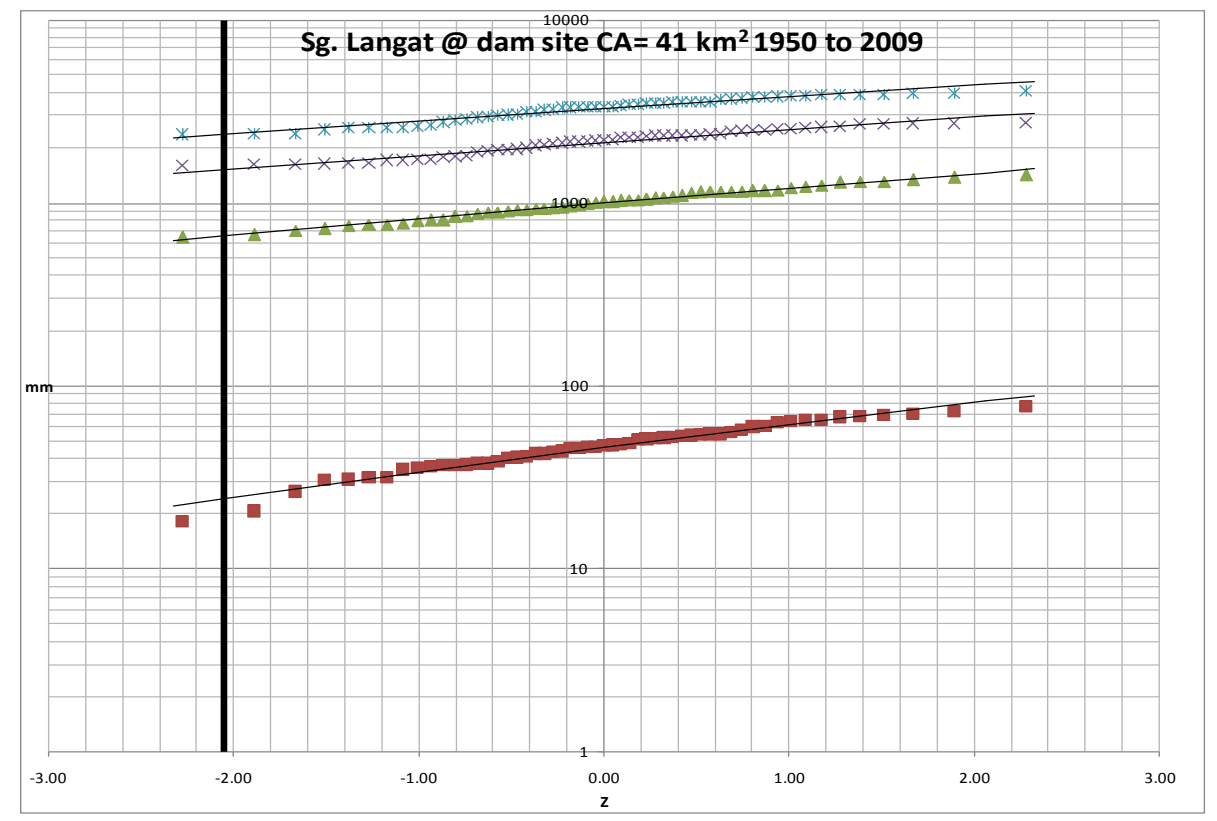

Figure 2: Drought Sequence Analysis

Note:

Square: 1 month, Triangle: 12 month, Cross: 24 month, Star: 36 month,Z $=-2.054$ denotes a 1:50-year low flow event 
In the DSA analysis, synthetic DSA was prepared a prior to the latter accounts for the percentage of failure to supply the target yield or meeting the demand by drawing down the reservoir active storage. A $98 \%$ reliability criterion is mostly adopted for water supply project undertakings. This technique of water balance calculation requires fairly long hydrometric records. Shorter records which do not include the known low flow episode would skew the results of the yield estimation. Experiences in Malaysia showed that a slightly higher yield could be harnessed using this long-term flow records vis-à-vis a conventional DSA approach. However, it must be borne in mind that these two methodologies in yield estimation essentially differed from one another in the context of yield definition.

For calculation using long-term monthly water balance, the reliable yield is likely to be overestimated if the hydrometric database is short. This essentially means that the most critical drought is not taken into consideration. Other screening techniques which are suitable for preliminary assessment of the reservoir yield were presented in Gould-Dincer model (McMahon et al, 2007), Kuria and Vogel (2014) and others. These techniques provide first hand screening tool in light of the data shortage and other pertinent hydrometric information. These techniques are suitable and useful for a limited case of single reservoir configuration and a firsthand estimation of both storage capacity requirement and critical period. Furthermore, the impact of climate change could also be included in the SYR model (McMahon et al, 2007).

A global data set of 729 unregulated river flows of at least 25 year of records was collated to derive a Storage-Yield-Reliability (SYR) water yield climate change assessment model by Kuria and Vogel (2014). This SYR model is basically a statistical linearized multiregression model using essential variables, such as inflow statistics, storage capacity, and probability of non-occurrence or return period. These variables are mostly statistically significant parameters amongst other minor variables such as the physical properties of the reservoir scheme. The set of database adopted by Kuria and Vogel (2014) was similar to the paper by McMahon et al. (2007). Using the same technique, the yield or behavior analysis (BA) was then carried out for 
the purpose to correlate the hydrological and physical variables of the dam/reservoir scheme, mainly for water supply purpose. The reliability criteria considered were for $90 \%, 95 \%$, and $98 \%$. As a result, a total of 12,413 cases were simulated in the development of an empirical multi-regression model.

The independent variables were the live storage, inflow statistics of mean, standard deviation, and skewness coefficient of the unregulated flows, the return periods in the forms of normal standard score.

\subsection{Methodology: Reservoir Yield Assessment}

\subsection{Mode Of Reservoir Operation}

The definition, "yield" has been defined differently in Malaysia. In order to avoid ambiguity and confusion mainly on the interpretation of yield results, in the context of this study, "yield" is defined as the steady and continuous supply of water that is:

- withdrawn, or/and diverted, or/and abstracted directly from rivers/lakes without the provision of some forms of storage facility, this is further known as run-of-river yield,

- abstracted directly from the reservoir and delivered to the water treatment plant by a long-haul pipeline system, in the case of a direct supply reservoir system, and

- Made available by diversion and/or abstraction at the intakes downstream and, in case of shortfall, the remaining water sources are timely augmented by the reservoir releases, mostly in the upper catchment, in the case of a regulating reservoir system.

This continuous raw water supply to the WTPs could not be maintained indefinitely, as along the ways there might be probable causes in terms of meteorological and climatic events (to a certain extent, in operation interruption due to pollution issue is ignored) that might interrupt the smooth supply of raw water to the treatment facilities. Therefore, design period is closely related to probabilistic low flow event. This is normally termed as return period or probability of nonoccurrence of low flow equal or less than the design 
flow. The design of drought period i.e. 1:50-year drought or 2\% drought is normally adopted in Malaysia.

Other than the stipulated level of water security and reliability of source water supply, extra cautionary measure is also being incorporated in the design criteria for both direct supply and regulating reservoir schemes as well. The purpose of this criterion is to ensure timely refilling of the reservoir to its brim after a continuous period of drawdown during dry season. In the conventional practice adopted in Malaysia, normally a 36-month carryover period is specified in tandem with the 1:50-year return period criteria.

An extended carryover or critical period is basically not taken primarily due the longer refilling period which will exert unduly pressure on both effectiveness and efficiency of the reservoir operation while releasing waters during an extended drier period and also its ability to be able to refill itself by the natural catchment runoff subsequently.

The carryover period (also known as critical period) is defined in the context of this study as the period, either based on a daily or monthly time scale, firstly from depleting the reservoir storage from full level to empty at the top of the dead storage elevation or level. After that, the reservoir is into the refilling phase until reaching the full supply level. The carryover period of 36 months is conservatively imposed to ensure that the reservoir will be refilled after drastic reservoir depletion during an extended period of 1:50-year severity. In contrast, if the carryover period is extended beyond 36 months, it essentially means a less stringent rule on the yield and capacity exercise of the reservoir scheme. As such, a slightly higher yield could be harnessed in this regard at the expense of lax rule on the period of refilling. Hence, the reservoir could be refilled in a much longer period of time. This rule however can be relaxed based on a case-by-case evaluation basis. As a matter-of-fact, this imposition of critical period is unique to the Malaysian water industry.

\subsection{Results and Discussions}


Yield estimations using the DSA and long term approaches were carried out based on existing dam schemes in Selangor and Kuala Lumpur. (1) Selangor-Tinggi, (2) Langat, and (3) Semenyih schemes are operated under the regulating reservoir scheme mode. On the other hand, three other smaller schemes such as, (4) Klang Gates, (5) Batu, and (6) Subang Lake are based on direct supply mode where the raw water from the reservoir are directly delivered to the respective WTPs via pipeline by gravity. The results were presented based on schemeby-scheme basis.

\subsection{Yield Analysis: Drought Sequence Approach}

In the original design of the Selangor-Tinggi dam scheme by regulating reservoir mode of operation, both Selangor and Tinggi dam releases make up the difference in deficit at the Bestari Jaya intake approximately $30 \mathrm{~km}$ further downstream of the Selangor dam site. On the other hand, Tinggi dam has a smaller catchment reservoir which cannot be refilled on time with its natural runoff. Therefore, a pumping refill scheme of $150 \mathrm{Mld}$ in capacity located in the middle reach of the Selangor river could accelerate the refilling of the reservoir during higher flow regime. On the contrary, due to its larger catchment area and storage capacity, Selangor reservoir is nevertheless expected to refill at the end of the twice-annually monsoon season from April to June and October to December.

These voluminous waters should be released ahead of time as it takes more than 15- 18 hours to reach the intake point. Using the updated DSA, the joint operation of Selangor and Tinggi dams could result in about 3000 Mld in net reliable yield. This basically confirmed independently on the findings of other subsequent studies carried out after the completion of the joint reservoir operation schemes. The reliable yield of Langat scheme was slightly lower, about 446 Mld vis-à-vis the plant capacity of $454 \mathrm{Mld}$. This however only constitutes in a minor difference that could be possibly attributed to different assumptions adopted in respective undertaking. With this in mind, a perfect match in yield could not be realized in any plausible circumstances. Thus, a smaller margin of difference of about $5 \%$ is perhaps acceptable in the practice and convention. 
On the other hand, the reliable yield of Semenyih dam scheme was higher, at about 764 Mld vis-à-vis the existing treatment plant capacity of 636 Mld. The WTP is known to operate by overloading even during normal period. This appears to corroborate well with apparent higher yield than the design capacity of the WTP. There is perhaps potential for upgrading and retrofitting of the WTP. Klang Gates and Batu dams are both representative of the dual-purpose reservoir scheme where they are functioning as both flood mitigation and domestic water sources for Wangsa Maju, Bukit Nanas and Sungai Dua WTPs. This therefore limits further expansion in their reservoir capacities. The reliable yield of Klang Gates and Batu dams were 131 Mld and 127 Mld respectively, consistently at least on the same order of magnitudes as their original design capacities of 145 Mld and 112 Mld.

Subang Lake dam is the smallest scheme amongst others. By this limitation in physical setting, the reliable yield was estimated at about 19 Mld vis-à-vis the existing North Hummock WTP capacity of about 23 Mld. The reservoir however took a slightly longer time, i.e. extending into a 48-month period, to recover to its full capacity after continuous drawdown during a 1:50-year design drought period.

In spite of this, operation of the WTP appears to be able to buffer these rare shortfalls by curtailing production during period of critical droughts. Plans are also in the pipeline to raise the capacity of the reservoir either by raising the reservoir capacity or converting the existing direct supply mode of operation into a pump storage scheme. Excess water can be transferred via pumping from the nearby Buluh river during high stage. The storage drawdown curves for all dam schemes are presented in Figure 3. 

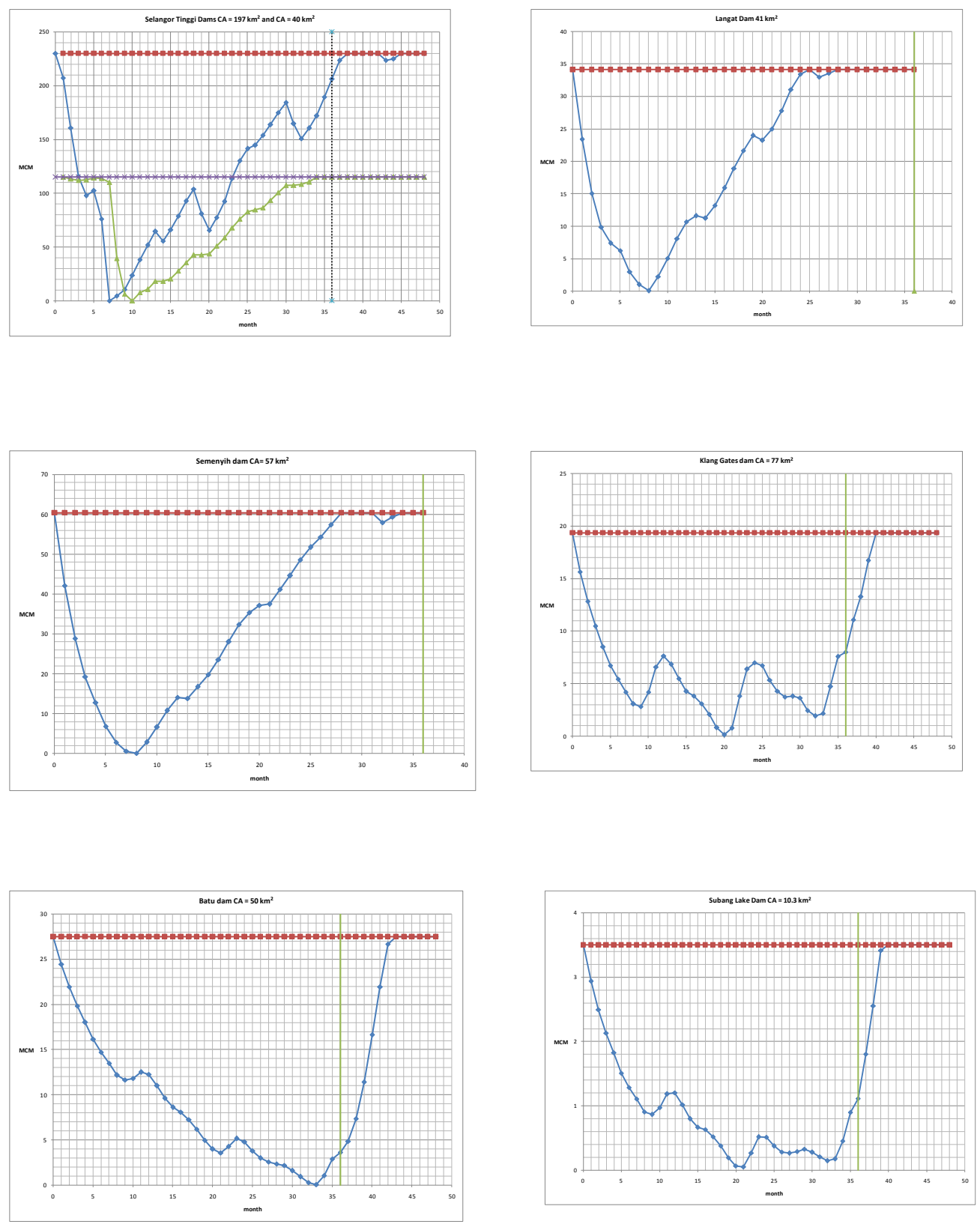

Figure 3: Reservoir Drawdown Curve 


\subsection{Long Term Operational Yield Analysis}

The sequential peak analysis (SPA) utilizes long term available hydrometric records in the operational study. This long term series includes both high and low flow episodic events in measured/gauged or inferred by proxy at the streamflow stations. This is particularly important if all the drought flow episodes are included in the flow time series.

In terms of yield criteria, the percentage of failure to supply is predetermined at an acceptable level, normally for water supply scheme; a $2 \%$ failure or alternatively, $98 \%$ reliability is acceptable. For this study, it is also highlighted that the 1:50-year return period and $2 \%$ failure rate are similar. The number of months that the reservoir fails to provide adequate raw waters sources, other than pollutant flushing episode, is counted. This is further expressed in terms of percentage of failure. Normally, failure to supply means that the reservoir capacity has reached its dead storage. In terms of critical period, the long-term calculation needs not rely on a full-empty-full cycle strictly. Some of the critical periods as opposed to DSA runs, can last for more than 60 months without refilling up to their respective full supply levels. This depends on the low flow episode encountered in the time series.

Selangor-Tinggi dam scheme regulates about $60 \%$ of the annual average runoff at the existing Bestari Jaya intake. The estimated yield of the twin regulating reservoir scheme was consistent vis-à-vis DSA approach, i.e. 3000 Mld with a 300-Mld constant release past the intake weir. Drawdown curves of both Selangor and Tinggi dams showed several occasions where both reservoirs were empty. The period of severity was by far the worst drought occurrence during 1991-1992 and 1997-1998 El Nino events. The most recent severe drought event experienced in Selangor was during 2013-2014. reservoirs were depleted almost to the bottom but was recovered shortly with higher reservoir inflows during the monsoon months of November and December. The drawdown curves of both reservoirs are presented in Figure 4. 
Langat dam showed frequent drawdowns had been taken place in the simulation results from 1950 to 2008. On the contrary, Semenyih dam appeared to be resilient with potentials for future expansion of reservoir water supply scheme with its fewer drawdown episode. Both hydrological and physical factors are believed to contribute to vast difference in reservoir drawdown behavior for these two dams that are located within the same Langat river basin. Firstly, a higher hydrological regime prevails in the Semenyih river basin especially its physical location where the dam catchment could be a receptor for both higher precipitation and downpour seasons from Northwestern and southwestern monsoons. Secondly, the reservoir size of Semenyih dam is almost double the size of Langat dam., This therefore could help to increase the yield significantly. For both Klang Gates and Batu dams, the reservoir drawdowns showed that the critical drawdown periods were from 1976 to 1979 instead of known El Nino event of 1982-1983 and 1997-1998. The yield results were generally consistent to the DSA approach. Perhaps due to its relative smaller capacity, Subang Lake dam scheme yield using long term approach did not differ from the results obtained using the DSA approach. The most severe drought event occurred in 1997-1998 and was coincidental to the worst El Nino event in the century. Figure 4 shows the reservoir drawdown curves for various reservoir schemes

\subsection{Independent Verification By Kuria And Vogel (2014)}

Independent yield verification was also carried out for existing dam schemes in Selangor and Kuala Lumpur. The input variables were related to the hydrological and physical inputs such as long term sample statistics of inflows, such as, mean, standard deviation, skewness coefficient and the storage capacity of the reservoir. It is assumed that live storage was implicitly used to represent the extensiveness of underground networks. The standard normalized score of $Z$ varied with the reliability to be adopted. For a 1:50-year return period, the standardized $\mathrm{Z}$ score was 2.054.

The results are consistent with the actual WTP capacities for the existing dam schemes. The only exception was a slightly higher gross yield by SYR model (Kuria and Vogel, 2014) for Semenyih dam 
scheme. Table 1 shows a summary of the gross yield results and other relevant parameters used in the calculation. Figure 5 shows excellent agreement between the estimated gross yield by SYR and the existing gross yields of the reservoir system. Although Kuria and Vogel (2014) model did not explicitly deduct the amount of water loss due to evaporation from the lake surface area, this might in a way results in overestimation of the reliable yield. However, it is also opinioned that due to constant drawdown period when the releases were made, only a small quantity of water will be lost due to shrinking of lake surface area.

The Kuria and Vogel (2014) model did not explicitly deduct the amount of water loss due to evaporation from the lake surface area, and this might in a way results in overestimation of reliable yield. However it is also opinioned that due to constant drawdown when the releases were made, only a small quantity of water will be lost due to the shrinking lake surface area.

Even if the loss due to surface evaporation were taken into the water balance equation, the difference is insignificant. In summary, the regression model proposed by Kuria and Vogel (2014) can only be used at least for the first screening of reliable yield estimation as it was originally intended.

One of the shortcomings of this SRY screening model was on the application of yield estimation to the Asia region as only a small fraction of database from Asia region (58) was part of the 729 river basins. These databases are mostly obtained from Australia, Continental Europe, and USA. For tropic Asia region, such as Malaysia, there are fewer representative river basins that were adopted in the model development. Nevertheless, comparison of yield results using various techniques is the first screening stage before embarking to a more elaborated study undertaking at the next stage of the yield estimation assignment. 


\begin{tabular}{|l|l|l|l|l|l|l|l|l|l|}
\hline \multicolumn{7}{|c|}{ Estimated gross yield using Kuria and Vogel (2014) } \\
Dam & $\begin{array}{l}\text { CA } \\
\mathbf{k m}^{2}\end{array}$ & $\begin{array}{l}\text { CA } \\
\text { km }\end{array}$ & $\begin{array}{l}\text { WTP } \\
\text { Gross } \\
\text { yield }\end{array}$ & $\begin{array}{l}\text { live } \\
\text { storage }\end{array}$ & mean & SD & skew & $\begin{array}{l}\text { G0- } \\
\text { year } \\
\text { yield }\end{array}$ & $\begin{array}{l}\text { 50- } \\
\text { year }\end{array}$ \\
\hline & dam & intake & Mld & MCM & MCM/yr & $\begin{array}{l}\text { MC M/yr } \\
\text { Mield }\end{array}$ & nd & $\begin{array}{l}\text { MC } \\
\text { M/yr }\end{array}$ & Mld \\
\hline $\begin{array}{l}\text { Selangor } \\
\text { Tinggi }\end{array}$ & 237 & 1554 & 3300 & 345 & 2010.9 & 410.3 & 0.25 & 1198 & 3283 \\
\hline Langat & 41 & 254 & 544 & 34.1 & 349.6 & 77.9 & 0.53 & 184 & 504 \\
\hline Semenyih & 57 & 571 & 751 & 60.4 & 716.0 & 161.0 & 0.52 & 363 & 995 \\
\hline Klang Gates & 77 & n.a. & 145 & 19.3 & 83.5 & 22.0 & 0.86 & 50 & 137 \\
\hline Batu & 50 & n.a. & 115 & 27.5 & 61.7 & 14.6 & 0.66 & 44 & 120 \\
\hline Subang lake & 10.3 & n.a. & 23 & 3.5 & 12.7 & 3.0 & 0.14 & 8 & 22 \\
\hline
\end{tabular}

Table 1: Estimated 1:50-year Gross Yields by Kuria and Vogel (2014)

NOTE: $\mathrm{CA}=$ catchment area

$\mathrm{SD}=$ standard deviation

$\mathrm{WTP}=$ water treatment plant 
Figure 4: Reservoir Drawdown Curves: Long Term Run
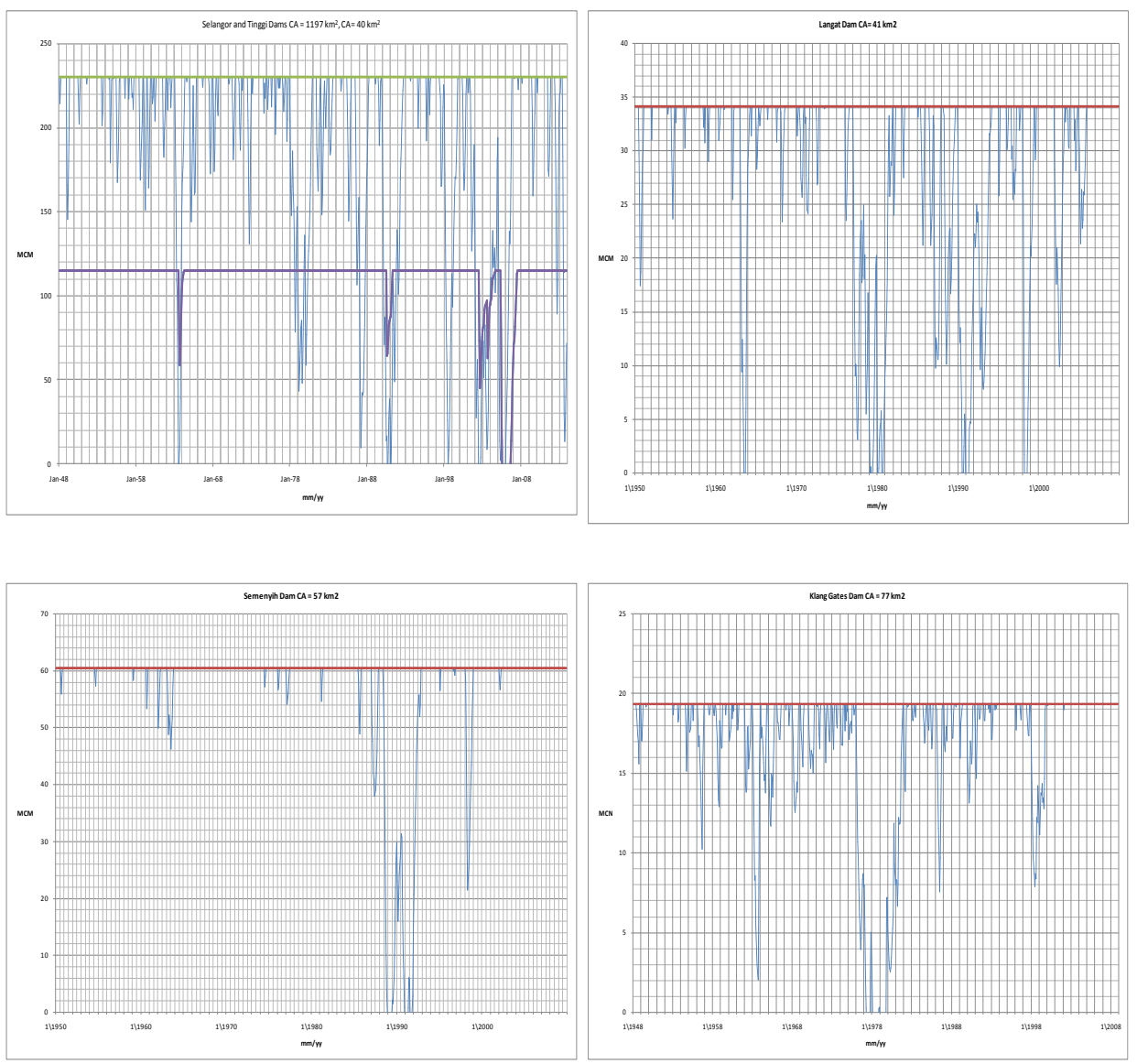


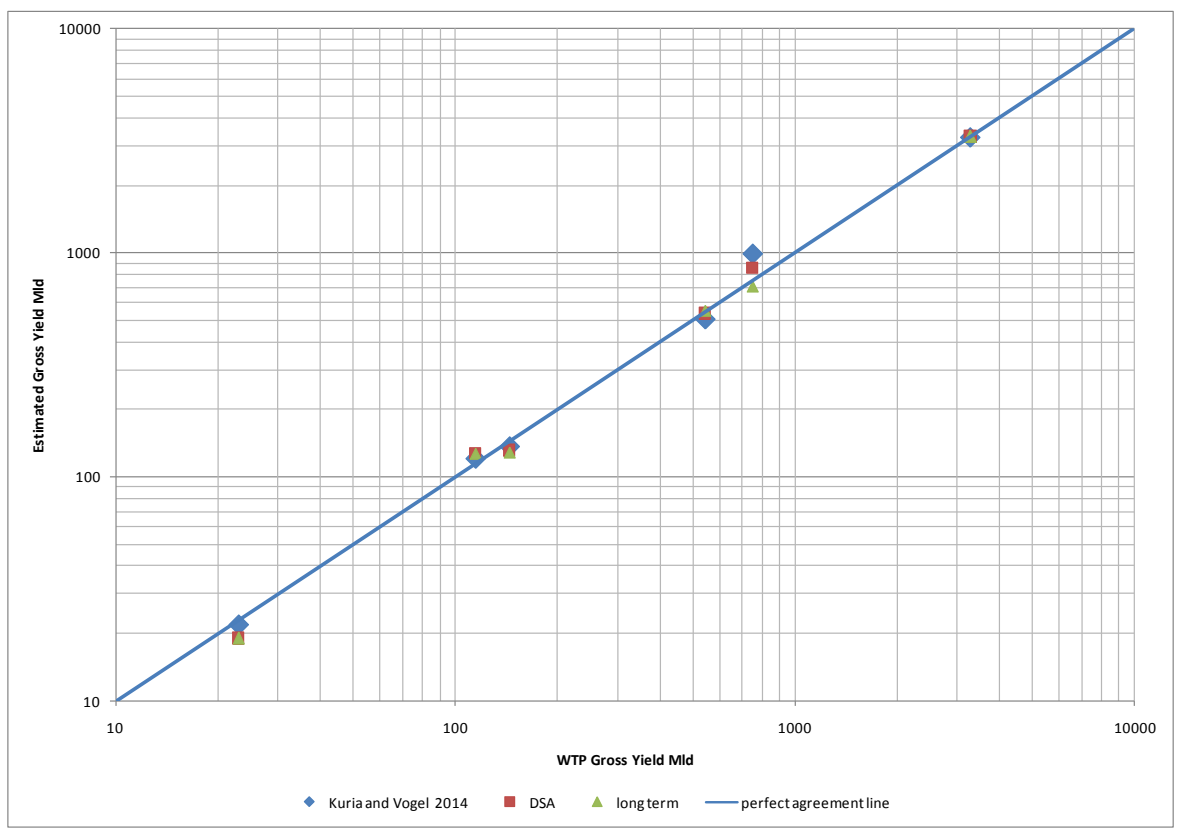

Figure 5: Comparison of WTP capacity and Estimated Gross Yields by Various Methods

\begin{tabular}{|l|l|l|l|l|}
\hline \multirow{2}{*}{$\begin{array}{l}\text { Dam } \\
\text { Scheme }\end{array}$} & $\begin{array}{l}\text { WTP } \\
\text { capacity }\end{array}$ & $\begin{array}{l}\text { DSA } \\
\text { approach }\end{array}$ & $\begin{array}{l}\text { Long } \\
\text { term } \\
\text { approach }\end{array}$ & $\begin{array}{l}\text { Kuria } \\
\text { and } \\
\text { Vogel, } \\
\mathbf{2 0 1 4}\end{array}$ \\
\cline { 2 - 5 } & Mld & Mld & Mld & Mld \\
\hline $\begin{array}{l}\text { Selangor } \\
\text { Tinggi }\end{array}$ & 3300 & 3300 & 3300 & 3283 \\
\hline Langat & 544 & 536 & 551 & 504 \\
\hline Semenyih & 751 & 851 & 708 & 995 \\
\hline $\begin{array}{l}\text { Klang } \\
\text { Gates }\end{array}$ & 145 & 131 & 128 & 137 \\
\hline Batu & 115 & 127 & 127 & 120 \\
\hline $\begin{array}{l}\text { Subang } \\
\text { lake }\end{array}$ & 23 & 19 & 19 & 22 \\
\hline
\end{tabular}

Table 2: Comparison of Gross Yield by Various Techniques and Methods for Dam Schemes in Selangor 


\subsection{Conclusions}

The purposes of this study is to review reliable yield that could be harnessed by six reservoir schemes in the state of Selangor in Malaysia. This study provides up-to-date hydrometric information up to 2008 (2014 for Selangor-Tinggi reservoir scheme). During the earlier days of dam design undertaking, hydrological analysis was carried out using limited information. After many years of operation, more hydrometric database have been acquired, and it is imperative to review and reassess the reliable yields of various reservoir schemes.

The yield estimations for six reservoir schemes in Selangor were calculated based on both drought sequence analysis (DSA) and long term sequential peak analysis approaches. By convention, a 1:50-year return period or probability of low flow occurrence, and a 36 month duration carryover period was adopted. An independent verification was carried out using storage-yield-reliability (SYR) model by Kuria and Vogel (2014).

The results from three approaches were basically consistent with one another with some minor margin of difference of about $5 \%$. This is mainly contributed from the Semenyih dam scheme where the gross yield estimation differed in a larger margin. For a summary of the findings, Table 2 shows a comparison of gross yields of various reservoir schemes for dam schemes in Selangor.

\subsection{References}

F.W. Kuria, and R.M. Vogel, A global water supply yield model with uncertainty analysis. Environmental Research Letter9, Iopscience.iop.org (2014)

I. Nagy, K. Asante-Duah and I Zsuffa, Hydrological dimensioning and operation of reservoir. Springer, Dordrecht, Germany (2002)

M. Johnson, DD. Ratnayaka, and MJ. Brandt, Twort's Water Supply, $6^{\text {th }}$ Edition, Butterworth-Heinemann, London, UK (2009)

TA. McMahon and AJ. Adeloye, Water resources yield, first edition, Water Resources Publication, Littleton, CO, USA (2005) 
TA. McMahon, and RG. Mein, River and reservoir Yield. Water Resources Publication, Littleton, CO. USA (1986)

TA. McMahon, GGS. Pegram, RM. Vogel and MC. Peel, Review of Gould-Dincer Reservoir Storage-Yield-Reliability Estimates. Advances in Water Resources, 30, 1873-1882 (2007)

WMO, Manual of Low Flow Estimation and Prediction. Operational Hydrology Report: 50. World Meteorological Organization, Geneva, Switzerland (2008) 